\title{
Epididymal origin of a coiled-tail sperm defect in a boar
}

\author{
W. V. Holt \\ Institute of Zoology, Department of Reproduction (Nuffield Building), Zoological Society of \\ London, Regent's Park, London NWI 4RY, U.K.
}

\begin{abstract}
Summary. The development of a tail-coiling defect in spermatozoa from a Welsh boar was studied by light and electron microscopy. The onset of tail-coiling was coincident with the passage of spermatozoa through the epididymis, since only cells isolated from regions of the duct distal to the caput epididymidis exhibited this characteristic. An intermediate form of this abnormality was detected in the proximal corpus epididymidis, where migration of the cytoplasmic droplets mainly occurred. It is suggested that defective migration of the cytoplasmic droplet might be associated with the pathogenesis of the coiled-tail defect in this animal.
\end{abstract}

\section{Introduction}

After their formation during spermatogenesis, spermatozoa undergo a period of maturation in the epididymis before they become fertile. Certain ultrastructural, biochemical and biophysical changes then take place, which can be correlated with the progress of the spermatozoa towards the distal region of the epididymis (for reviews, see Bedford, 1974; Bedford \& Cooper, 1978). In normal circumstances the morphological changes primarily involve modifications of the sperm head (Bedford, 1965; Jones, 1971), and the migration and eventual loss of the cytoplasmic droplet (Hancock, 1957).

This paper presents findings on the morphology of spermatozoa from different levels of the epididymis in a boar known to ejaculate a high proportion of spermatozoa with morphologically abnormal tails.

\section{Materials and Methods}

The Welsh boar was culled from a commercial insemination unit because of the persistently high frequency of abnormal spermatozoa in its ejaculates. Counts made at the unit over a 2-month period showed that $40-80 \%$ of the ejaculated spermatozoa possessed tightly coiled tails. The motility of these sperm samples had been variously recorded as 'poor', 'fair' or 'good'.

The animal was moved to the Royal Veterinary College, London, for further observation; there, an ejaculated semen sample of normal volume $(192 \mathrm{ml})$ was obtained, which contained $1.52 \times 10^{9}$ spermatozoa $/ \mathrm{ml}$ in the sperm-rich fraction, and a low frequency of dead spermatozoa $(\approx 3 \%)$. The sperm density was determined using a haemocytometer, and the proportion of dead spermatozoa was estimated from eosin-nigrosin smears.

The boar was castrated surgically under halothane anaesthesia, and samples of epididymal tissue from 8 sites along the left epididymis (defined in Table 1) were fixed by immersion in a solution containing picric acid, formaldehyde and glutaraldehyde (PFG: Jones, 1973). These samples were subsequently osmicated and dehydrated, embedded in araldite and sectioned. The 
spermatozoa within the epididymal tubules were then examined by electron microscopy. The right epididymis was fixed whole in buffered formal-saline.

Samples of epididymal spermatozoa from the 8 sites in the left epididymis were obtained by centrifugation of the used PFG-fixing fluids, smears were then prepared and examined by phase-contrast microscopy. Duplicate counts, of 100 cells each, were performed on these smears, correlating the position of the cytoplasmic droplet (i.e. proximal, medial, distal or absent) with the extent of tail bending. Sperm tails were classified as extended (PI. 1, Fig. 1), bent (Pl. 1, Fig. 2) or coiled (Pl. 1, Fig. 3). Similar counts were also performed on smears prepared from an ejaculate obtained 5 months before castration.

\section{Results}

\section{Light microscopy}

Table 1 gives the results of the counts sampling the left epididymis; examples of the three main classes of spermatozoa encountered are shown in Pl. 1, Figs 1-3. There was a close association between the incidence of deformed sperm tails and the position of the cytoplasmic droplet; few defective spermatozoa were found in the initial segment or proximal caput epididymidis, where the cytoplasmic droplets were almost exclusively proximally situated. In site 4 most of the spermatozoa (59\%) were of an intermediate type possessing a distal cytoplasmic droplet about which the flagellum was bent but not coiled (PI. 1, Fig. 2). Similar spermatozoa were detected at a lower frequency in sites 5 and 6 , but were virtually absent from sites 7 and 8 . The cauda epididymidis (sites 6,7 and 8) contained an appreciable number of spermatozoa with cytoplasmic droplets still in the proximal position; these also possessed extended tails. Conversely, only a very small number of spermatozoa possessed extended tails and a distal cytoplasmic droplet.

\section{PLATE 1}

Figs 1-3. Three classes of boar epididymal spermatozoa isolated from sampling sites 1 (Fig. 1), 4 (Fig. 2) and 8 (Fig. 3), and characterized as extended, bent and coiled respectively. $\times 1000$.

Fig. 4. Longitudinal section through the neck and middle-piece of a spermatozoon found in sampling site 1 . The cytoplasmic droplet is situated symmetrically about the flagellum, and contains few structural features. $\times 27500$.

Fig. 5. Longitudinal section through the middle-piece of a bent spermatozoon found at sampling site 4. The cytoplasmic droplet is laterally displaced, and shows a local concentration of membranous structures. The mitochondria show some irregularities in size and shape (arrows). The point of bending is associated with the position of the cytoplasmic droplet, its distal boundary being fixed at the annulus. $\times 22000$.

\section{PLATE 2}

Fig. 6. Sections of spermatozoa from sampling site 4. A number of transverse sections of middle-pieces, within cytoplasmic droplets, are present, the droplets all showing lateral displacement and localized accumulations of membranous structures. In one case, the mitochondria are abnormally small (arrow). $\times 11500$.

Fig. 7. Section through the cytoplasmic droplet of a spermatozoon from sampling site 5 . Approximately 8 transverse sections through different regions of the same flagellum are enclosed by one plasma membrane. Disruption of the axial filament complex (AF) is evident in sections through the middle-piece. $\times 43400$.

Fig. 8. Longitudinal section through a spermatozoon from sampling site 5 , showing bending and coiling of the flagellum, breakage of the axial filament complex, and grossly abnormal mitochondria. The plasma membrane is largely absent. $\times 11750$. 


\section{PLATE 1}

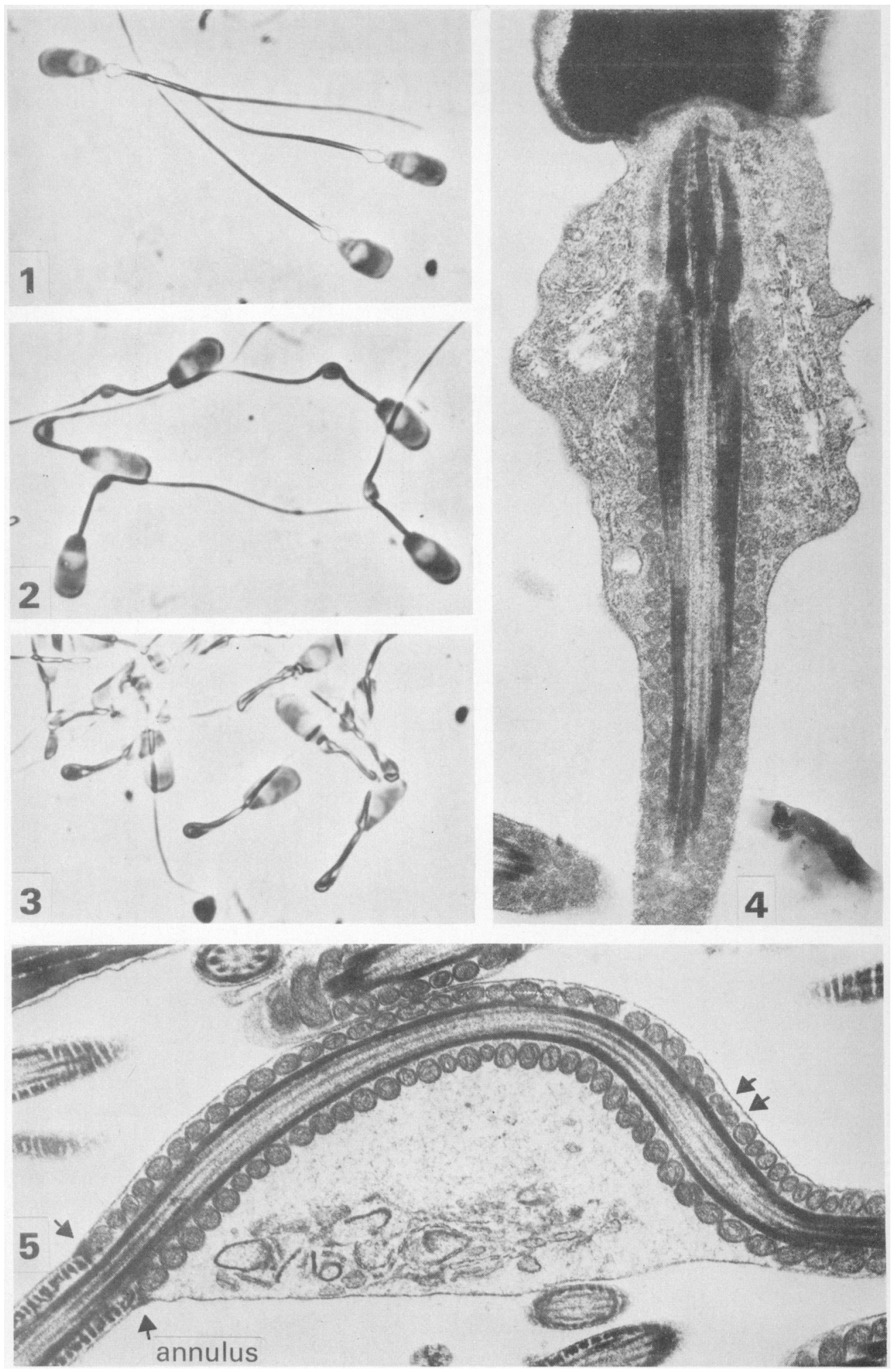




\section{PLATE 2}

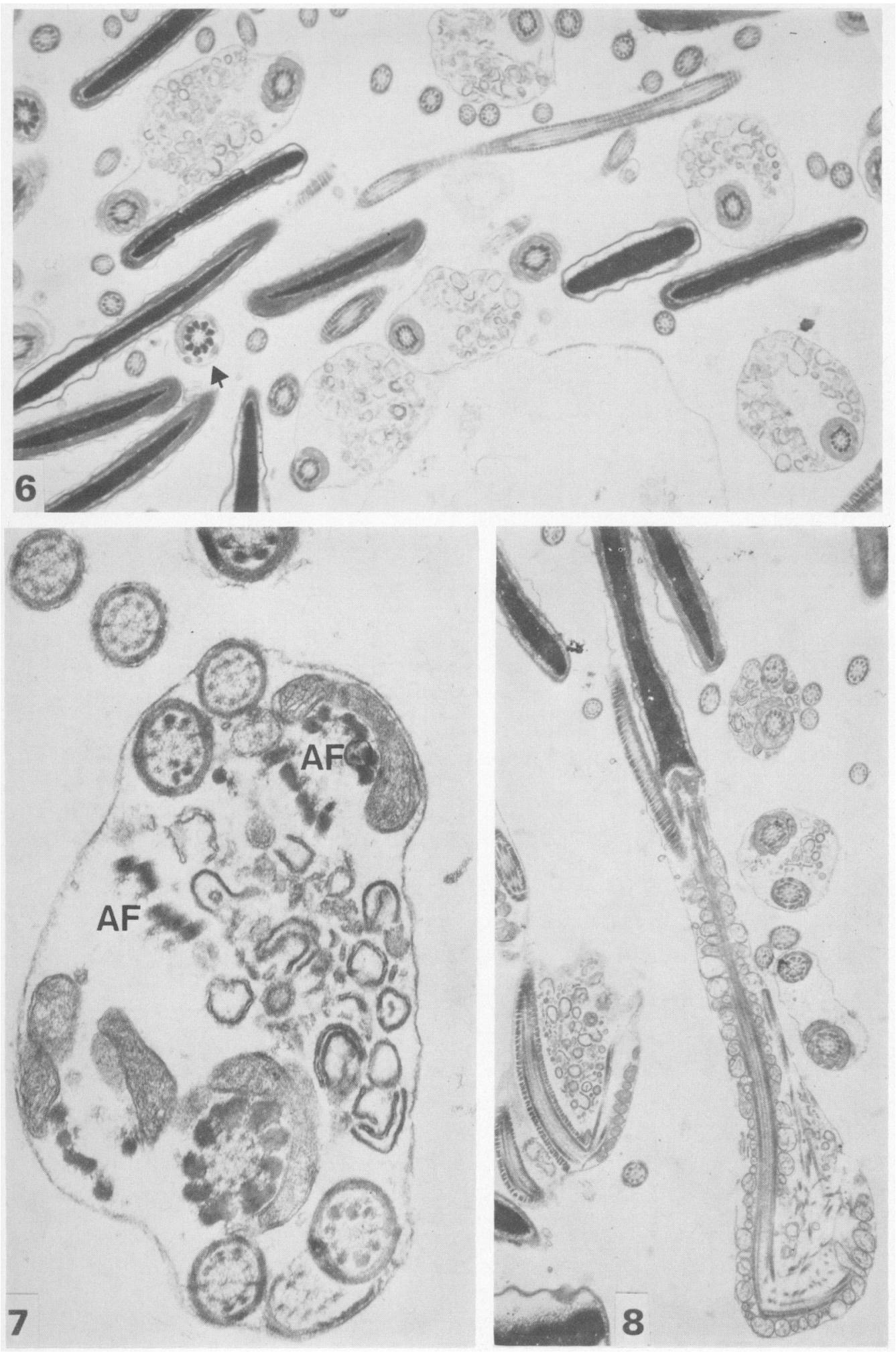


Table 1. The incidence (\%), in various regions of the left epididymis of a boar, of proximal, medial or distal cytoplasmic droplets in three classes of spermatozoa, distinguished by their tail morphology

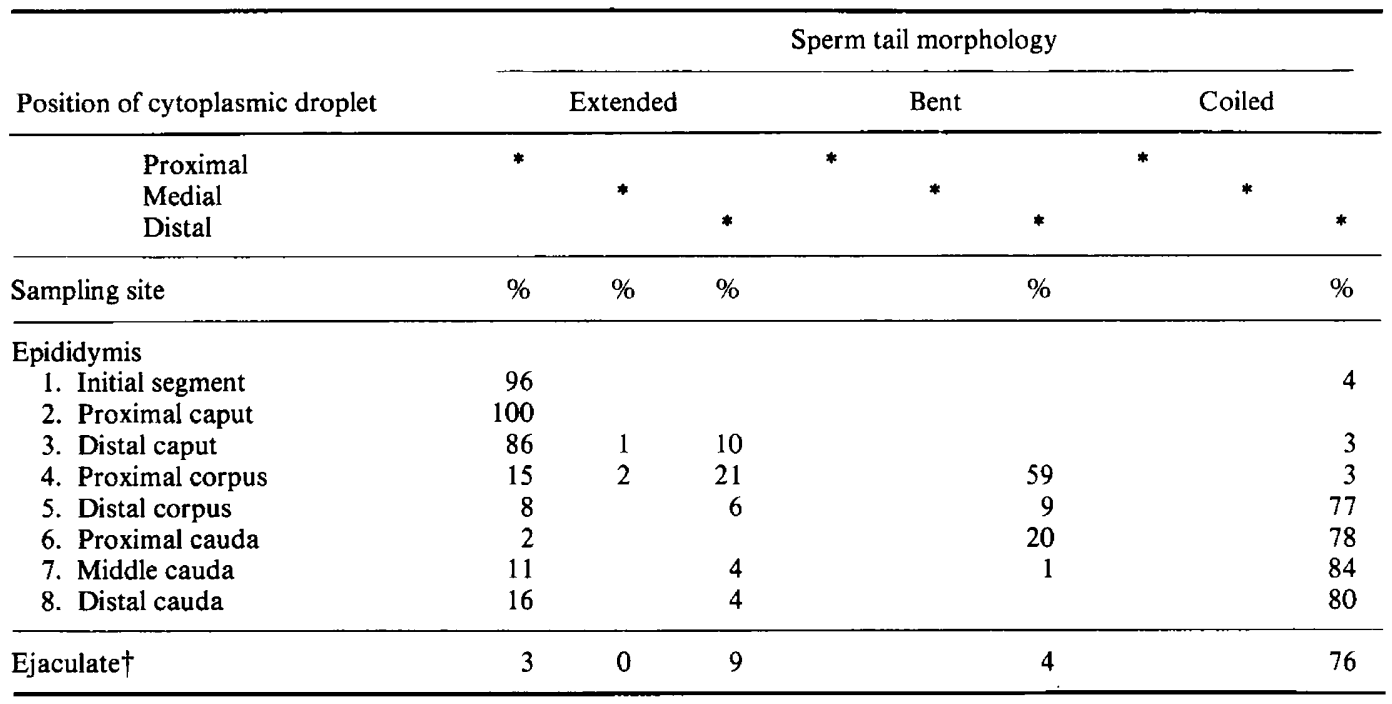

Results are means of duplicate counts.

$\dagger 8 \%$ ejaculated spermatozoa were classified as 'extended, cytoplasmic droplet absent'.

Counts made from ejaculated spermatozoa were essentially similar to those of the cauda epididymidis, except that a low frequency $(\approx 8 \%)$ of extended spermatozoa lacking cytoplasmic droplets was detected. These were not encountered in the samples of epididymal spermatozoa.

\section{Electron microscopy}

Luminal spermatozoa at site 1 had proximal cytoplasmic droplets situated symmetrically about the middle-piece and contained amorphous cytoplasm (PI. 1, Fig. 4). The mitochondrial sheaths, principal pieces and end pieces of the spermatozoa from this region were of normal appearance, and no abnormalities of the plasma membrane or axial filament complex were observed.

Some difficulty was experienced in finding sufficient spermatozoa for ultrastructural examination within the tubules of sites 2 and 3 , but those found closely resembled the spermatozoa of site 1 .

Spermatozoa from site 4 had cytoplasmic droplets that were situated around the distal region of the middle-pieces and contained localized accumulations of membranous structures (Pl. 1, Fig. 5; Pl. 2, Fig. 6). In transverse sections (Pl. 2, Fig. 6), it was evident that the middle-piece was, in general, situated to one side of the cytoplasmic droplet, the membranous structures having accumulated towards the other side, whilst a region of empty cytoplasm filled the intervening space. Longitudinal sections of the middle-piece confirmed this local distribution of organelles within the cytoplasmic droplets (Pl. 1, Fig. 5), and the distal region of the middle-piece appeared to be curved within the confines of the cytoplasmic droplet. The cytoplasmic droplet was never observed posterior to the annulus; this structure also defined the posterior limit of tail curvature (Pl. 1, Fig. 5). The mitochondria of spermatozoa from site 4 were mainly of regular size and normal appearance, but in some regions of the middle-piece small or damaged mitochondria were observed (P1. 1, Fig. 5; Pl. 2, Fig. 6, arrows). No abnormalities of the axial filament complex were observed. 
Spermatozoa from sites 5-8 exhibited various structural abnormalities. The cytoplasmic droplets were situated towards the distal region of the middle-piece and, when sectioned transversely, contained two or more transversely or obliquely sectioned regions of the sperm tail (Pl. 2, Figs 7 and 8). Membranous structures were also present within the cytoplasmic droplets, but their localized distribution, seen in site 4 , was less readily apparent. The mitochondria of spermatozoa in these regions were often grossly irregular and almost devoid of their internal membranous structure, the plasma membrane overlying these mitochondria being broken or, in places, absent (Pl. 2, Fig. 8). The axial filament complex was frequently disorganized (PI. 2, Fig. $7, \mathrm{AF}$ ) particularly in the region of the middle-piece.

\section{Discussion}

Abnormalities of boar and bull ejaculated spermatozoa involving tail-coiling, breakage and disruption of the axial filament complex, or disorganization of the mitochondria, have been noted by a number of authors (for example, Blom, 1966; Van Duijn \& Geuze, 1972; Kojima, 1978) and the onset of some of these defects has been associated with sperm maturation in the epididymis of the bull (Blom \& Birch-Andersen, 1966; Koefoed-Johnsen \& Pedersen, 1971; Wenkoff, 1978) and the boar (Settergren \& Nicander, 1972).

The present findings show that a similar defect in the boar also became evident as the spermatozoa passed from the distal caput to the proximal corpus epididymidis. Additionally, an intermediate stage in the development of this abnormality has been detected, and a correlation noted between the onset of tail-bending and the migration of the cytoplasmic droplet. Spermatozoa sampled from epididymal regions proximal to site 4 , the proximal corpus epididymidis, mostly displayed normal tail morphology, although a small percentage of coiled-tails was noted even in the initial segment. The intermediate stage of tail-coiling was most evident in site 4 ; in site 5 the tail-coiling defect was fully developed in most spermatozoa.

Only one previous case (Hancock, 1955) has been documented in which the migration of the cytoplasmic droplet was identified as a correlative factor in the pathogenesis of a sperm defect; in that bull the result was physical separation of the sperm heads and tails.

The ultrastructural features of the present sperm tail abnormality are different from those previously reported. For example, whereas tail-coiling in this boar began in the distal region of the middle-piece, Koefoed-Johnsen \& Pedersen (1971) showed that in the "Dag defect", a similar phenomenon found in bulls (Blom, 1966), the middle-piece was only occasionally involved. Loss or displacement of axonemal doublets in the junction between the middle-piece and main-piece was also noted in the same study (Koefoed-Johnsen \& Pedersen, 1971), but in the present study disruption of the axonemal complex was apparent only in tail sections which were involved in tight coils, and may therefore represent secondary damage (see Jones, 1975, for review). The complement of hydrolytic enzymes found in the cytoplasmic droplet (Dott \& Dingle, 1968; Garbers, Wakabayashi \& Reed, 1970) may also contribute towards degradation of the tail structures.

Settergren \& Nicander (1972) observed swelling and shortening of the mitochondria in defective boar spermatozoa, but noted that this abnormality occurred mainly in regions of mitochondrial sheath surrounded by the cytoplasmic droplet. Furthermore, although this abnormality was judged to be of epididymal origin, few spermatozoa were found with distal cytoplasmic droplets.

The factors which may cause bending or coiling of the sperm-tail were reviewed by Jones (1975), who saw this process mainly as a response to adverse conditions such as osmotic stress, inhibition of metabolic activity or cationic imbalance. Ploen \& Håkansson (1978) also showed, however, that experimental cryptorchidism in rabbits could predispose spermatozoa towards the development of tail defects during epididymal transit. The onset of the sperm tail defect in this 
boar cannot therefore be definitively explained on the information available, but the subtle variations in structural damage noted in the various case reports suggest that defective spermiogenesis may be as likely a fundamental cause of this abnormality as epididymal malfunction.

I thank Mr W. P. Unsworth (Meat \& Livestock Commission) who initially noted the sperm defect studied here; Professor J. L. Hancock for access to materials; Professor D. Noakes for the surgical procedures; and Mr E. Edwards and Mr T. J. Dennett for help with the specimen collection and the preparation of the figures.

\section{References}

Bedford, J.M. (1965) Changes in fine structure of the rabbit sperm head during passage through the epididymis. J. Anat. 99, 891-906.

Bedford, J.M. (1974) Report of a workshop: maturation of the fertilizing ability of mammalian spermatozoa in the male and female reproductive tract. Biol. Reprod. 11, 346-362.

Bedford, J.M. \& Cooper, G.W. (1978) Membrane fusion events in the fertilization of vertebrate eggs. In Cell Surface Reviews, Vol. 5, pp. 65-125. Eds G. Poste \& G. L. Nicholson. Elsevier/North Holland, Amsterdam.

Blom, E. (1966) A new sterilizing and hereditary defect (the "Dag-defect") located in the bull sperm tail. Nature, Lond. 209, 739-740.

Blom, E. \& Birch-Andersen, A. (1966) The ultrastructure of a new hereditary sterilizing defect (the Dag-defect) in the bull sperm tail. In Proc. 5th Wld Congr. Fert. Steril., Stockholm, pp. 602-605. Excerpta Medica (ICS No. 133), Amsterdam.

Dott, H.M. \& Dingle, J.T. (1968) Distribution of lysosomal enzymes in the spermatozoa and cytoplasmic droplets of bull and ram. Expl Cell Res. 52, 523-540.

Garbers, D.L., Wakabayashi, T. \& Reed, P.W. (1970) Enzyme profile of the cytoplasmic droplet from bovine epididymal spermatozoa: Biol. Reprod. 3, 327-337.

Hancock, J.L. (1955) The disintegration of bull spermatozoa. Vet. Rec. 67, 825-826.

Hancock, J.L. (1957) The morphology of boar spermatozoa. J. Roy. Microsc. Soc. 76, 84-97.
Jones, R.C. (1971) Studies of the structure of the head of boar spermatozoa from the epididymis. J. Reprod. Fert., Suppl. 13, 51-64.

Jones, R.C. (1973) Preparation of spermatozoa for electron and light microscopy. J. Reprod. Fert. 33, 145-149.

Jones, R.C. (1975) Fertility and infertility in mammals in relation to sperm structure. In The Biology of the Male Gamete, pp. 343-365. Eds. J. G. Duckett \& P. A. Racey. Academic Press, London.

Koefoed-Johnsen, H.H. \& Pedersen, H. (1971) Further observations on the Dag-defect of the tail of the bull spermatozoon. J. Reprod. Fert. 26, 77-83.

Kojima, Y. (1978) Fine structure of boar sperm abnormality: tightly coiled tail. Japan. J. Anim. Reprod. 24, 89-92.

Ploen, L. \& Häkansson, N. (1978) Abnormal epididymal spermatozoa two to thirty-five days after a brief experimental cryptorchidism in the rabbit. Int. $J$. Androl. 1, 250-261.

Settergren, I. \& Nicander, L. (1972) Formation and fine structure of abnormal mitochondrial sheaths in spermatozoa of an infertile boar. Proc. 7th Int. Congr. Anim. Reprod. \& A.I., Munich, pp. 459-462.

Van Duijn, C., Jr. \& Geuze, J.J. (1972) Ultrastructural midpiece defects in spermatozoa from the subfertile great Yorkshire boar "Ard". Proc. 7th Int. Congr. Anim. Reprod. \& A.I., Munich, pp. 470-473.

Wenkoff, M.S. (1978) A sperm mid-piece defect of epididymal origin in two Hereford bulls. Theriogenology 10, 275-281.

Received 5 June 1981 